\title{
An optimised protocol for detection of SARS-CoV-2 in stool
}

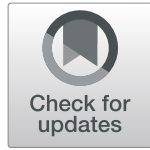

Tianqi Li ${ }^{1,2 \dagger}$, Enriqueta Garcia-Gutierrez ${ }^{1 \dagger}$, Daniel A. Yara ${ }^{1}$, Jacob Scadden ${ }^{1}$, Jade Davies ${ }^{1}$, Chloe Hutchins ${ }^{1}$, Alp Aydin ${ }^{3}$, Justin O'Grady ${ }^{3}$, Arjan Narbad ${ }^{1}$, Stefano Romano ${ }^{1 *}$ (D) and Lizbeth Sayavedra ${ }^{\text {** }}$

\begin{abstract}
Background: SARS-CoV-2 has been detected in stool samples of COVID-19 patients, with potential implications for faecal-oral transmission. Compared to nasopharyngeal swab samples, the complexity of the stool matrix poses a challenge in the detection of the virus that has not yet been solved. However, robust and reliable methods are needed to estimate the prevalence and persistence of SARS-CoV-2 in the gut and to ensure the safety of microbiome-based procedures such as faecal microbiota transplant (FMT). The aim of this study was to establish a sensitive and reliable method for detecting SARS-CoV-2 in stool samples.

Results: Stool samples from individuals free of SARS-CoV-2 were homogenised in saline buffer and spiked with a known titre of inactivated virus ranging from 50 to 750 viral particles per $100 \mathrm{mg}$ stool. Viral particles were concentrated by ultrafiltration, RNA was extracted, and SARS-CoV-2 was detected via real-time reverse-transcription polymerase chain reaction (RT-qPCR) using the CDC primers and probes. The RNA extraction procedure we used allowed for the detection of SARS-CoV-2 via RT-qPCR in most of the stool samples tested. We could detect as few as 50 viral particles per $100 \mathrm{mg}$ of stool. However, high variability was observed across samples at low viral titres. The primer set targeting the $\mathrm{N} 1$ region provided more reliable and precise results and for this primer set our method had a limit of detection of 1 viral particle per mg of stool.
\end{abstract}

Conclusions: Here we describe a sensitive method for detecting SARS-CoV-2 in stool samples. This method can be used to establish the persistence of SARS-CoV-2 in stool and ensure the safety of clinical practices such as FMT.

Keywords: FMT, COVID19, RT-qPCR, Stool, Clinical-test

\section{Background}

The global pandemic caused by SARS-CoV-2, poses an imminent threat to the global population. From December 2019 until the 22nd of June 2021, the number of confirmed cases stands at 179 million and rising, leading to an unprecedented challenge on health systems internationally. SARS-CoV-2 causes severe acute respiratory syndrome - infecting human cells by binding to the

\footnotetext{
* Correspondence: Stefano.Romano@quadram.ac.uk;

Lizbeth.Sayavedra@quadram.ac.uk

Tianqi Li and Enriqueta Garcia-Gutierrez are shared first-authorship.

${ }^{1}$ Gut Health and Microbes, Quadram Institute Bioscience, Norwich Research Park, Norwich, UK

Full list of author information is available at the end of the article
}

receptor angiotensin converting enzyme 2 (ACE2). ACE2 is an inflammation regulator expressed by epithelial cells located in the lung, liver, and gastrointestinal tract. It has been reported that gastrointestinal symptoms, such as diarrhoea, nausea, and vomiting, may be observed in up to $61 \%$ of cases [1]. These gastrointestinal symptoms may be linked to the severity of the COVID-19 disease based on viral load and the degree of viral replication in the gut [2-5]. SARS-CoV-2 RNA has been detected in patient stool both during infection and after patients have apparently recovered - indicated by a lack of viral detection from nasal swab [6]. Viable SARS$\mathrm{CoV}-2$ has been isolated from stool samples [6-8], which suggests that there is a potential risk of faecal-oral

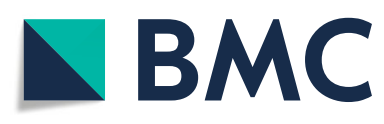

(c) The Author(s). 2021 Open Access This article is licensed under a Creative Commons Attribution 4.0 International License, which permits use, sharing, adaptation, distribution and reproduction in any medium or format, as long as you give appropriate credit to the original author(s) and the source, provide a link to the Creative Commons licence, and indicate if changes were made. The images or other third party material in this article are included in the article's Creative Commons licence, unless indicated otherwise in a credit line to the material. If material is not included in the article's Creative Commons licence and your intended use is not permitted by statutory regulation or exceeds the permitted use, you will need to obtain permission directly from the copyright holder. To view a copy of this licence, visit http://creativecommons.org/licenses/by/4.0/ The Creative Commons Public Domain Dedication waiver (http://creativecommons.org/publicdomain/zero/1.0/) applies to the data made available in this article, unless otherwise stated in a credit line to the data. 
transmission [9-13]. Hence, monitoring the viral load in stool is of crucial importance to maintain public health and limit viral spreading. A few studies have reported that the viral load in stool samples $\left(10^{2}-10^{7}\right.$ genome copies $\left.\mathrm{mL}^{-1}\right)$ is several orders of magnitude lower than in saliva $\left(10^{8}\right.$ genome copies $\left.\mathrm{mL}^{-1}\right)[14,15]$. However, methods for the detection of the virus in stool have been poorly described. Robust and reliable methods are an urgent need, as microbiota-based therapies such as faecal microbiota transplantation (FMT) would need to rely heavily on the accurate screening of donor stools to ensure the absence of SARS-CoV-2 and guarantee patient safety [16].

For both nasal swabs and saliva samples, RT-qPCR is the most used diagnostic tool for detecting SARS-CoV2, with many assays targeting the SARS-CoV-2 nucleocapsid $(\mathrm{N})$ gene $[17,18]$. For example, the commonly used Centers for Disease Control and Prevention (CDC) RT-qPCR test targets two regions of the $\mathrm{N}$ gene (N1 and N2). However, the faecal matrix has properties distinct from those of respiratory samples [19-21], therefore making the reliable detection of SARS-CoV-2 challenging. Recently, a few methods have been described for the detection of SARS-CoV-2 in stool samples [16, 22, 23]. However, the potentially low concentration of SARS-CoV-2 in faeces and the unique features of the sample matrix require optimised protocols to improve the recovery of viral RNA and increase our ability to detect the virus in stool samples. To address this need, we developed a reliable and sensitive method for SARS$\mathrm{CoV}-2$ detection in stool.

\section{Results}

Several recent studies indicate that viable SARS-CoV-2 can be detected in stool samples of COVID-19 patients $[6,7]$, suggesting that a possible risk for faecal-oral transmission exists. However, methods for the detection of SARS-CoV-2 in stool have been poorly assessed so far, and an optimised protocol is currently missing. Here, we describe an optimised protocol (Fig. 1A) to improve the detection of SARS-CoV-2 in stool samples. We performed our experiments using samples collected either before the current pandemic started (before October 2019) or from healthy donors who did not display and had not previously displayed symptoms of COVID19. We used a commercially available SARS-CoV-2 stock, which was quantified through digital PCR by the manufacturer and was therefore used to infer the limit of detection of our approach. Extracted RNA samples were then used to detect SARS-CoV-2 via RT-qPCR with primer sets N1 and N2 [24]. We assessed how various steps throughout the RNA extraction influence the detection of SARS-CoV-2 in stool and report recommendations for optimizing these procedures in future clinical settings.

First, we spiked different volumes of an inactivated viral stock in stool samples and extracted the RNA with or without ultrafiltration (Supplementary Table 1). We obtained positive amplifications for both the N1 and N2 regions using both approaches. Without ultrafiltration we obtained positive amplifications with both $\mathrm{N} 1$ and N2 primer sets down to 2900 viral particles (vp) per $100 \mathrm{mg}$. In contrast, the addition of ultrafiltration allowed us to detect positive amplifications with both primer sets down to $725 \mathrm{vp}$ per $100 \mathrm{mg}$ (Supplementary Table 1). Hence, for all further tests we included an ultrafiltration step in our protocol. We then assessed what viral concentration was more reliably detected across stool types. Thus, we used a viral stock that had been accurately quantified using digital PCR and we spiked three stool samples using concentrations ranging from 50 to $750 \mathrm{vp}$ per $100 \mathrm{mg}$. We were able to detect SARS-CoV-2 in all the stool samples we tested. The lowest concentration we could detect was 50 vp per $100 \mathrm{mg}$ (Table 1), but a high variability amongst samples was observed for the lower concentrations (50-200 vp per $100 \mathrm{mg}$ ). This variability might be the result of the stool characteristics, for example, mucus and fibre content, as it has been previously reported that stool features can inhibit molecular assays [19-21].

We then selected the two lowest concentrations that gave reliable results (100 and $200 \mathrm{vp}$ per $100 \mathrm{mg}$ ) to estimate the limit of detection (LoD) of our method. The stool sample used to determine the LoD was exclusively used for this experiment (i.e. was not used to create the previous datasets). We performed repeated extractions after spiking the homogenised stool sample with $100 \mathrm{vp}$ per $100 \mathrm{mg}$ (6 replicates in total) and $200 \mathrm{vp}$ per $100 \mathrm{mg}$ (7 replicates in total). As negative control, we also extracted 6 non-spiked stool aliquots, all of which resulted negative in the RT-qPCR assay. For the N1 primer set all samples spiked with either 100 or 200 vp per $100 \mathrm{mg}$ resulted positive in the RT-qPCR assay (Table 2). In contrast, for the N2 primer set, 3 out of 6 and 7 out of 7 samples gave positive amplification for the 100 and $200 \mathrm{vp}$ per $100 \mathrm{mg}$ spikes, respectively (Table 2). Based on this data our approach has a LoD, defined as the lowest concentration at which all tested samples gave positive results in at least one RT-qPCR replicate, of $100 \mathrm{vp}$ per $100 \mathrm{mg}\left(1 \mathrm{vp} \mathrm{mg}^{-1}\right)$ for the $\mathrm{N} 1$ primer set and 200 vp per $100 \mathrm{mg}\left(2 \mathrm{vp} \mathrm{mg}^{-1}\right)$ for the N2 primer set. These data are consistent with previous reports that highlighted the higher sensitivity of the $\mathrm{N} 1$ assay compared to the N2 assay [25].

Subsequently, we tested our method on 24 additional stool samples to estimate the variability in detection based on stool type and infer the specificity and 


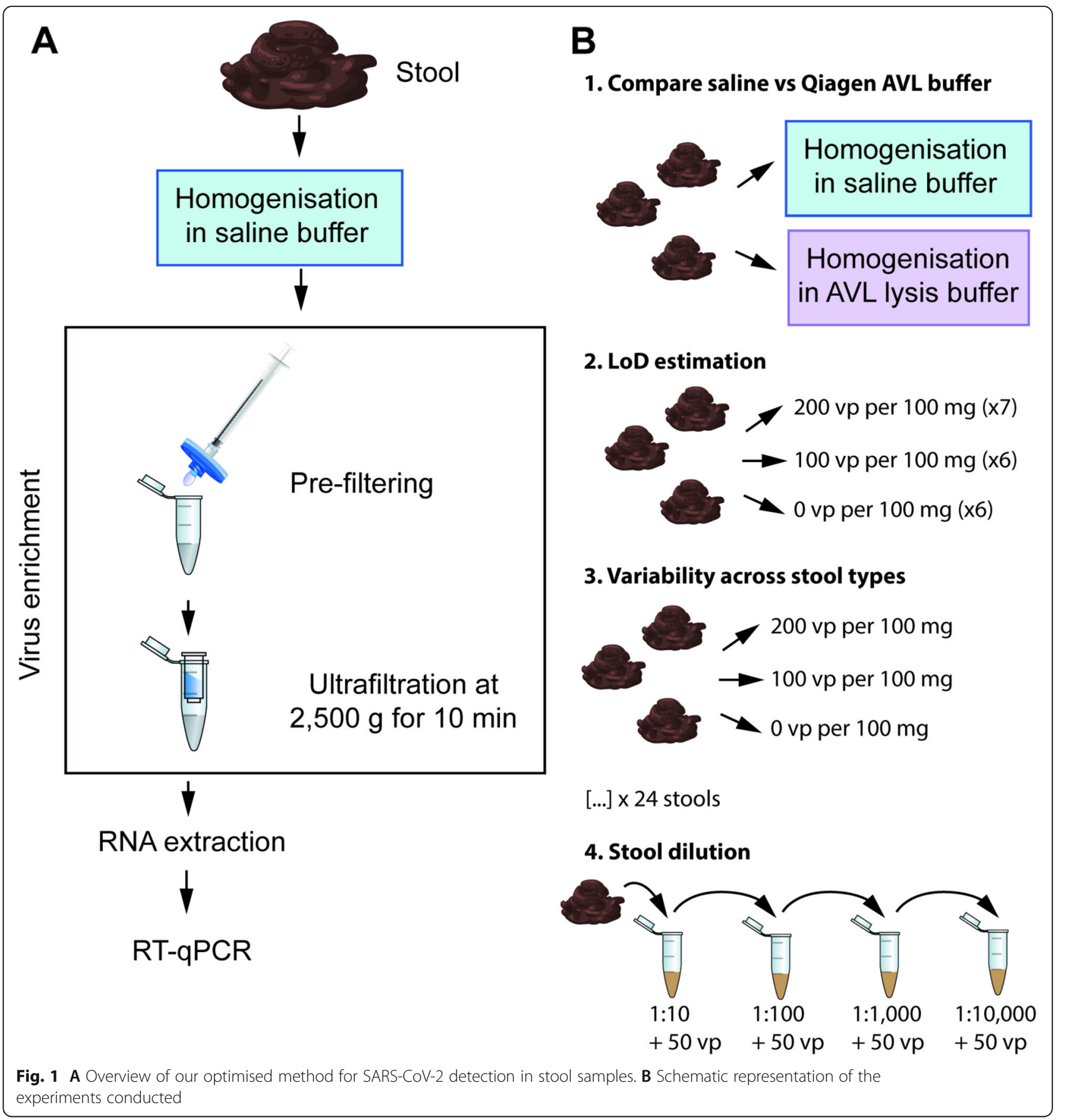

sensitivity of our assay. We were able to detect the virus reproducibly and consistently across the majority of the samples with average $\mathrm{Ct}$ values ranging from 32.6 to 38.2 and from 32.0 to 37.7 for the $\mathrm{N} 1$ and $\mathrm{N} 2$ regions, respectively (Fig. 2). Using these 24 samples we estimated that our method has a sensitivity and a specificity of $100 \%$ for both the N1 and N2 primer set (Table 3).

As we consistently detected viral particles in stool samples diluted in saline buffer, we investigated whether homogenising faecal material in the Qiagen AVL buffer would affect RNA recovery. For this test, we used the same three stool samples initially used to assess the lowest viral load detectable. When Qiagen AVL buffer was used, a higher variability was observed across samples (Table 1). Furthermore, we observed that the faecal material does not fully homogenise in the AVL buffer (Supplementary Fig. 1), suggesting that this might potentially affect the release of viral particles from the stool matrix.

Faecal material could potentially inhibit the PCR affecting the sensitivity and reproducibility of molecular 
Table 1 Ct values of RT-qPCR using RNA extracted from sample homogenised in saline buffer and AVL buffer

\begin{tabular}{|c|c|c|c|c|c|c|c|c|c|c|c|c|}
\hline \multirow{3}{*}{$\begin{array}{l}\text { Viral } \\
\text { load }^{\text {a }}\end{array}$} & \multicolumn{6}{|c|}{ Saline buffer } & \multicolumn{6}{|c|}{ AVL buffer } \\
\hline & \multicolumn{2}{|l|}{ Stool 1} & \multicolumn{2}{|l|}{ Stool 2} & \multicolumn{2}{|l|}{ Stool 3} & \multicolumn{2}{|l|}{ Stool 1} & \multicolumn{2}{|l|}{ Stool 2} & \multicolumn{2}{|l|}{ Stool 3} \\
\hline & N1-mean & N2-mean & N1-mean & N2-mean & N1-mean & N2-mean & N1-mean & N2-mean & N1-mean & N2-mean & N1-mean & N2-mean \\
\hline 0 & - & - & - & - & - & - & - & - & - & - & - & - \\
\hline 50 & 34.8 & 36.2 & - & - & - & 33.5 & 35.2 & - & - & - & & - \\
\hline 100 & 34.8 & 36.3 & - & - & 34.2 & 32.5 & 34.9 & 35.2 & - & - & - & - \\
\hline 150 & 34.6 & 35.3 & 35.8 & - & 34.9 & 33.9 & 33.8 & 34.7 & 36.4 & - & - & - \\
\hline 200 & 34.2 & 34.0 & 35.9 & - & 34.2 & 33.0 & 33.5 & 33.9 & 35.8 & - & 37.2 & - \\
\hline 250 & 34.0 & 34.6 & 35.4 & - & 34.8 & 33.6 & 35.0 & 36.0 & 36.7 & - & 36.0 & - \\
\hline 500 & 32.8 & 33.6 & 34.2 & - & 33.7 & 33.5 & 35.1 & 36.3 & 36.2 & - & 35.4 & 36.7 \\
\hline 750 & 32.7 & 33.7 & 35.4 & 33.8 & 33.5 & 33.9 & 36.0 & - & 36.6 & - & 33.1 & 34.8 \\
\hline
\end{tabular}

${ }^{a}$ Numbers of viral particles spiked in $100 \mathrm{mg}$ of stool

- = Sample showed no Ct value

assays. Hence, we performed serial dilutions of a selected stool sample, spiked them with the same amount of virus (50 vp per dulution), and processed them using our method. This was done to verify whether a decreasing amount of faecal material would affect $\mathrm{Ct}$ values. Higher sample dilutions did not decrease Ct values nor increased the consistency of positive qPCR results (Supplementary Fig. 2).

Finally, we applied our method to saliva samples (Fig. 2). We could consistently detect the spiked virus in all saliva samples tested. Moreover, we observed that doubling the vp concentration clearly resulted in a decrease of $\mathrm{Ct}$ values. This trend was not observed in the 24 stool samples we processed (Fig. 2). Hence, we recommend using our approach as a qualitative rather than quantitative method.

\section{Discussion}

Initial reports indicate that the concentration of SARSCoV-2 in stool might be several orders of magnitude lower than in saliva [14, 15]. Moreover, the complexity of the stool matrix can affect the precision of molecular testing [19-21], posing additional challenges for the detection of the virus in stool samples. Hence, methods that can account for these limitations are needed to allow a robust and reliable detection of the virus in faeces. By concentrating the viral particles via ultrafiltration, we were able to develop a sensitive method to detect SARS-CoV-2 in faeces, with a LoD of $1000 \mathrm{vp} \mathrm{g}^{-1}$ for $\mathrm{N} 1$ and $2000 \mathrm{vp} \mathrm{g}^{-1}$ for N2. To the best of our knowledge, this is the lowest LoD so far described $[16,26]$. Manzoor et al. reported a LoD of $204 \mathrm{vp} \mathrm{g}^{-1}$ [27]. However, this was calculated as the lowest copy number that could be detected in stool spiked with extracted RNA, without considering the reproducibility of this measure across multiple replicates as we have reported in our study.

The method we describe has high sensitivity and specificity. It is worth noting that roughly half of the initial faecal slurry was used after centrifugation $(500-600 \mu \mathrm{L}$ of the $1 \mathrm{~mL}$ in which $100 \mathrm{mg}$ stool was homogenised). Hence, if we assume a homogeneous suspension, the $\mathrm{Ct}$ values we obtained are from roughly half the initial number of viral particles spiked. Moreover, following the recommendation in the RNA extraction kit manufacture's protocol we eluted the extract twice with $40 \mu \mathrm{L}$ buffer. Although the elution with this volume $(2 \times 40$ $\mu \mathrm{L})$ might increase the total yield of RNA, an elution with lower volume could result in a more concentrated extract and therefore, increase the sensitivity of the RTqPCR assay. Altogether these data indicate that, potentially, our method has room for further improvements by enhancing the separation between debris and supernatant to recover higher fractions of the slurry used in

Table 2 Overview of the limit of detected (LoD) experiments

\begin{tabular}{|c|c|c|c|c|}
\hline \multirow[b]{2}{*}{ Viral particles in $100 \mathrm{mg}$} & \multicolumn{2}{|l|}{ N1 } & \multicolumn{2}{|l|}{ N2 } \\
\hline & 100 & 200 & 100 & 200 \\
\hline Number of replicates & 6 & 7 & 6 & 7 \\
\hline SARS-CoV-2 positive ${ }^{a}$ & $6(100 \%)$ & $7(100 \%)$ & $3(50 \%)$ & $7(100 \%)$ \\
\hline Mean Ct (st. dev) & $32.6( \pm 0.8)$ & $31.4( \pm 0.5)$ & $32.8( \pm 0.4)$ & $32.1( \pm 0.5)$ \\
\hline
\end{tabular}

${ }^{a}$ Samples were considered positive if at least one RT-qPCR replicate showed $\mathrm{Ct}$ values $<40$ 


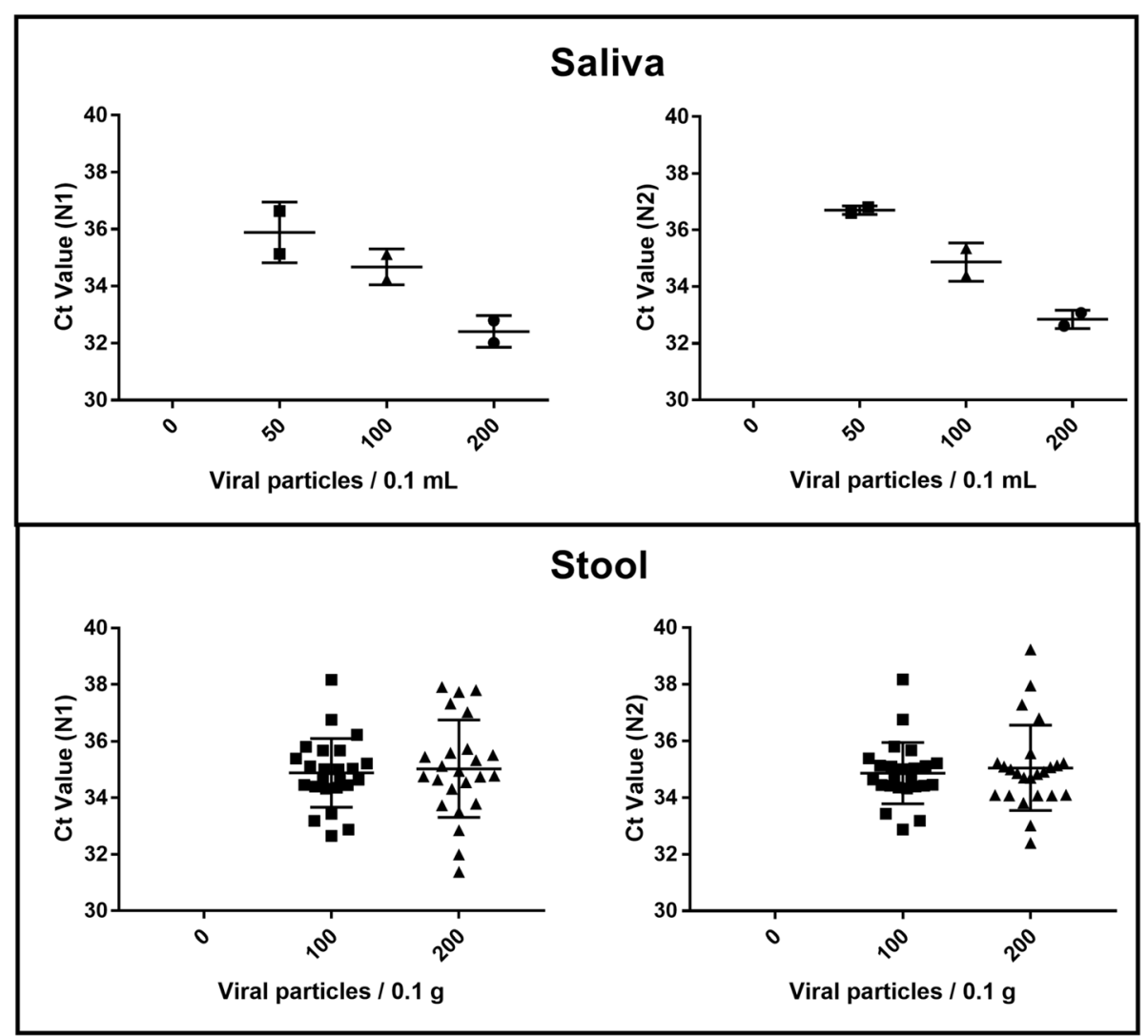

Fig. 2 Ct values obtained for the N1 and N2 regions used to detect SARS-nCoV-2 in saliva or stool samples. The average of two technical qPCR replicates is shown. In five stool samples only one replicate gave positive results, which have been included in the graphs

the RNA extraction and by using smaller volumes for RNA elution.

We report that diluting the stool samples in AVL leads to less accurate results. This observation is particularly relevant because in several studies, RNA has been extracted from stool samples by applying the standard manufacturers' protocol of the extraction kits [13, 28]. Such protocols recommend dissolving samples in extraction buffers (e.g. Qiagen AVL buffer), and are not necessarily optimised for stool samples. Our data indicate that depending on the stool matrix type, this procedure can reduce the efficiency of the RNA extraction and possibly underestimate the virus detection. Hence, we strongly recommend following optimised protocol for stool, like the one we discuss here, that require the dissolution of the sample in saline solution before RNA extraction.

\section{Conclusions}

Here we assess the technical challenges encountered while screening stool material for the presence of SARSCoV-2. We describe a robust approach to detect SARSCoV-2 in stool samples, having a LoD of 1 and 2 vp $\mathrm{mg}^{-1}$ for the $\mathrm{N} 1$ and $\mathrm{N} 2$ primer set, respectively. Although we could detect as low as 50 vp per $100 \mathrm{mg}$, a high variability can be observed between stool sample types when viral concentrations are low. We demonstrated that following standard manufacturer's RNA extraction protocols may not be sufficient to detect SARS$\mathrm{CoV}-2$ in stool samples as stool consistency and homogenisation media can affect the downstream assays. To improve detection, we strongly recommend homogenising the stool samples in saline solution first, then concentrating the viral particles with ultrafiltration. Our

Table 3 Sensitivity and specificity of the protocol we developed. Data refer to the 24 stool samples spiked with 100 viral particles per 100 mg. The $95 \%$ confidence interval is reported in brackets. A sample is considered positive if a single RT-qPCR replicate with $\mathrm{Ct}<40$ is detected for either the N1 or N2 primer set

\begin{tabular}{lll}
\hline Regions of $\boldsymbol{N}$ gene amplified & Sensitivity $(\boldsymbol{N}=\mathbf{2 4})$ & Specificity $(\boldsymbol{N}=\mathbf{2 4})$ \\
\hline N1 & $24 / 24(100 \%, \mathrm{Cl}=86-100)$ & $24 / 24(100 \%, \mathrm{Cl}=86-100)$ \\
N2 & $24 / 24(100 \%, \mathrm{Cl}=86-100)$ & $24 / 24(100 \%, \mathrm{Cl}=86-100)$ \\
\hline
\end{tabular}


method is sufficiently reliable to monitor the prevalence and persistence of the viral particles in the gut and can help in determining the safety of samples intended for use in FMT applications. To ensure the maximal safety for the patients, we propose that FMT donors should be screened following the recommendations here, and donor stool should be excluded even if a single $\mathrm{N}$ region (N1 or N2) or a single replicate per region gives a positive result due to the variability introduced by the stool matrix.

\section{Method}

\section{Sample preparation and RNA extraction}

Stool samples collected either before the COVID-19 outbreak (October 2019), or from donors who did not display and had not displayed symptoms of COVID-19 were weighed $(100 \mathrm{mg})$ and homogenised in saline solution $(0.89 \%$ w: $\mathrm{V} \mathrm{NaCl})$ with a ratio of $1: 10$ (w:v; $100 \mathrm{mg}$ in $900 \mu \mathrm{L}$ ) by vortexing for at least $1 \mathrm{~min}$. In an initial screening phase, we assessed the effect of an ultrafiltration step aimed at enriching viral particles before RNA extraction using a single stool sample. For these tests, we spiked the homogenised stool with different volumes of AMPLIRUN ${ }^{\circ}$ TOTAL SARS-CoV-2 CONTROL (VirCell Microbiologists, Spain) and then either directly extracted the RNA using the QIAamp Viral RNA Mini Kit (Qiagen, UK; CN 52,906) or, first enriched the viral particles by ultrafiltration and then extracted the RNA, as described below. Since the ultrafiltration step improved SARS-CoV-2 detection we added this step in all further RNA extractions.

All the following experiments were performed by spiking the homogenised stool samples with the inactivated stock solution of SARS-CoV-2 positive Q control, SCV2QC01-B, Qnostics (UK). We used this stock because it has been precisely quantified by the manufacturing company using digital PCR. The stock is available by the supplier (Randox Biosciences, UK) in transport media at a viral concentration of 10,000 digital copies (dC) $\mathrm{mL}^{-1}$. The homogenised stool samples $(1 \mathrm{~mL})$ were spiked with different concentrations of viral particles, centrifuged at 4,000 g for $10 \mathrm{~min}$, and then supernatants were filtered through $0.22 \mu \mathrm{M}$ syringe filters. Virus enrichments were then performed using ultrafiltration tubes (Sigma, UK; CN UFC810024) by loading $500 \mu \mathrm{L}$ of the filtrate and centrifuging at 2,500 $\mathrm{g}$ for $10 \mathrm{~min}$. The concentrated samples (around $50 \mu \mathrm{L}$ ) were used for RNA extraction using QIAamp Viral RNA Mini Kit, following the protocol provided by the manufacturer. Finally, the viral RNA was eluted in two aliquots of $40 \mu \mathrm{L}$ buffer AVE supplied with the kit as recommended by the manufacturer to increase the yield. An overview of the method we developed is reported in Fig. 1A. We first used three stool samples to assess the lowest amount of virus detectable with our approach. The same samples were then used to assess the effect of the solution used to homogenise the stool (Table 1). This was done by repeating the above protocol and homogenising the stool not in saline solution but in AVL Buffer (Qiagen, UK; CN 19,089), as recommended in the QIAamp Viral RNA Mini Kit manufacturer manual. Finally, 24 additional stool samples were then used to verify the variability of the assay across stool types and to infer the sensitivity and specificity of our protocol by extracting RNA after spiking them with 0,100 and 200 vp per $100 \mathrm{mg}$.

An additional stool sample was then used to calculate the limit of detection (LoD) of our method. The LoD, defined as the lowest concentration of virus at which all samples had at least one positive RT-qPCR replicate, was estimated as follows. A freshly collected stool sample was diluted in saline solution in the ratio specified above and then stored at $-20^{\circ} \mathrm{C}$ until further processing. After thawing, the homogenised stool sample was aliquoted and six and seven replicates were spiked with 100 or 200 vp per $100 \mathrm{mg}$, respectively. Six non-spiked replicates were also prepared. Samples were processed as described, and virus enrichment was performed using between 500 and $600 \mu \mathrm{L}$ of supernatant. RNA was extracted as described. To verify the absence of contamination in the reagents, we also performed RNA extractions using kit reagents only. As positive control, we extracted RNA from $10 \mu \mathrm{L}$ of the original stock used to spike the samples.

Finally, we selected one stool sample and performed serial dilution to verify whether decreasing the level of faecal material could improve the qPCR results. Here, $100 \mathrm{mg}$ of stool was homogenised in $900 \mu \mathrm{L}$ of saline solution. Subsequently, the homogenate was diluted down to 1:10,000 in 10-fold dilution steps. All dilutions were spiked to a final concentration of $50 \mathrm{vp} / \mathrm{sample}$. Samples were processed for RNA extraction and qPCR as described above. An overview of the experiments performed in this study is reported in Fig. 1B.

We then tested our method on two saliva samples that were collected before the start of the COVID-19 pandemic. Here, $100 \mu \mathrm{L}$ of saliva was diluted in $900 \mu \mathrm{L}$ of saline solution and were then spiked with the inactivated SARS-CoV-2 viral stock (SCV2QC01-B) with a final concentration of $0,50,100$ or 200 vp per $100 \mu \mathrm{L}$ of saliva. The samples were then processed using the same procedure described for stool.

\section{RT-qPCR assay}

Primer sets N1 and N2 (Integrated DNA Technologies, Belgium, 10,006,713) were used for identifying SARSCoV-2 with the Probe 1-Step Go No Rox or Probe 1Step Go Rox kits (PCR Biosystems) [24]. RT-qPCR was then performed in a Roche LightCycler 480 Instrument 
II or a StepOnePlus ${ }^{\text {nu }}$ Real-Time PCR System (Applied Biosystems ${ }^{\mathrm{ms}}$ ) using the following conditions: $50^{\circ} \mathrm{C}$ for $10 \mathrm{~min}, 95^{\circ} \mathrm{C}$ for $2 \mathrm{~min}, 45$ cycles of $95^{\circ} \mathrm{C}$ for $5 \mathrm{~s}$, $55^{\circ} \mathrm{C}$ for $30 \mathrm{~s}$, followed by $40^{\circ} \mathrm{C}$ for $30 \mathrm{~s}$. The Ct values were calculated, and samples were considered as positive only if they showed Cts lower than 40 cycles. RT-qPCR was always performed using two technical replicates. As the aim of this study was to verify the variability in detecting SARS-CoV-2 in stool samples with the intention of reporting robust guidelines for screening FMT material, we considered positive also samples for which only 1 RT-qPCR technical replicate gave positive amplification. To determine the $95 \%$ confidence interval for the specificity and the sensitivity we used the binom.test function in the R software [29].

\section{Abbreviations}

FMT: Faecal microbiota transplant; vp: Viral particles; LoD: Limit of detection

\section{Supplementary Information}

The online version contains supplementary material available at https://doi. org/10.1186/s12866-021-02297-w.

\section{Additional file 1.}

\section{Acknowledgements}

We thank Emma Flannagan and Dr David Vauzour for providing samples, Lee Kellingray, George Savva, and Sharlize Pedroza-Matute for fruitful discussions and Gemma Kay for provision of reagents. The authors wish to acknowledge the role of the NRP Biorepository in collecting and making available the samples used in the generation of this publication, and the patients who donated to the Biorepository. We thank Antonietta Hayhoe for helping the research team to comply with ethics and governance requirements.

\section{Authors' contributions}

$L T, E G-G, L S, S R$, JO and AN conceived the study; LT, EG-G, DAY, LS, CH, and SR performed experiments; JS, AA, and JD helped with protocol optimization: EG-G, DAY, SR, LS and AN wrote the manuscript with contributions from all authors. The author(s) read and approved the final manuscript.

\section{Funding}

This work was supported by funding from the QIB, the Biotechnology and Biological Sciences Research Council (BBSRC) Impact Accelerator Account (BB/S506679/1), Institute Strategic Programme Gut Microbes and Health (BB/ R012490/1) and its constituent projects BBS/E/F/000PR10355 and BBS/E/F/ 000PR10356, Institute Strategic Programme Microbes in the Food Chain BB/ R012504/1 and its constituent projects BBS/E/F/000PR10348, BBS/E/F/ 000PR10349, BBS/E/F/000PR10351, and BBS/E/F/000PR10352. JS and JD were supported by the UKRI-BBSRC Norwich Research Park Biosciences Doctoral Training Partnership (BB/M011216/1). The funding bodies did not have any role in the study design or execution or any other aspect of the manuscript preparation and submission.

\section{Availability of data and materials}

Data sharing is not applicable to this article as no datasets were generated or analysed during the current study.

\section{Declarations}

\section{Ethics approval and consent to participate}

Human tissue samples were accessed in accordance with the research protocol approved by the Faculty of Medicine and Health Sciences Research Ethics Committee (FMH REC) of the University of East Anglia (UEA) (FMH Reference 2013/2014-67 HT and R204719) and registered at http://www. clinicaltrials.gov/ (NCT03679533 and NCT02188238). These samples were obtained via the NRP Biorepository (Human Tissue Authority-licensed tissue bank, License number 11,208 ) under the ethics approval granted by the National Health Service Health Research Authority (NHS HRA) (East of EnglandCambridge East Research Ethics Committee, REC Ref 19/EE/0089; IRAS number 259,062). An additional stool sample was accessed through a study approved by the Quadram Institute Bioscience, Human Research Governance committee (IFR01/2015), and London - Westminster Research Ethics Committee (15/LO/2169). The latter trial is registered at http://www.clinicaltrials.gov (NCT02653001).

\section{Consent for publication}

Not applicable.

\section{Competing interests}

The authors declare that there are no conflicts of interest.

\section{Author details}

${ }^{1}$ Gut Health and Microbes, Quadram Institute Bioscience, Norwich Research Park, Norwich, UK. ${ }^{2}$ State Key Laboratory of Food Science and Technology, School of Food Science and Technology, Jiangnan University, Wuxi, China.

${ }^{3}$ Microbes in the Food Chain, Quadram Institute Bioscience, Norwich Research Park, Norwich, UK

Received: 12 March 2021 Accepted: 18 August 2021

Published online: 06 September 2021

\section{References}

1. Redd WD, Zhou JC, Hathorn KE, McCarty TR, Bazarbashi AN, Thompson CC, et al. Prevalence and characteristics of gastrointestinal symptoms in patients with severe acute respiratory syndrome coronavirus 2 infection in the United States: a multicenter cohort study. Gastroenterology. 2020;159(2): 765-7 e2.

2. Ng SC, Tilg H. COVID-19 and the gastrointestinal tract: more than meets the eye. Gut. 2020;69(6):973-4.

3. Gou W, Fu Y, Yue L, Chen G-d, Cai X, Shuai M, et al. Gut microbiota may underlie the predisposition of healthy individuals to COVID-19. medRxiv. 2020; https://doi.org/10.1101/2020.04.22.20076091.

4. Henry BM, de Oliveira MHS, Benoit J, Lippi G. Gastrointestinal symptoms associated with severity of coronavirus disease 2019 (COVID-19): a pooled analysis. Intern Emerg Med. 2020;15(5):857-9.

5. Jin X, Lian JS, Hu JH, Gao JB, Zheng L, Zhang YM, et al. Epidemiological, clinical and virological characteristics of 74 cases of coronavirus-infected disease 2019 (COVID-19) with gastrointestinal symptoms. Gut. 2020;69(6): 1002-9.

6. Wang WL, Xu YL, Gao RQ, Lu RJ, Han K, Wu GZ, et al. Detection of SARSCoV-2 in different types of clinical specimens. Jama-J Am Med Assoc. 2020; 323(18):1843-4

7. Amirian ES. Potential fecal transmission of SARS-CoV-2: Current evidence and implications for public health. Int J Infect Dis. 2020;95:363-70.

8. Zhang Y, Chen C, Song Y, Zhu SL, Wang DY, Zhang H, et al. Excretion of SARS-CoV-2 through faecal specimens. Emerg Microbes Infec. 2020;9(1): 2501-8

9. Holshue ML, DeBolt C, Lindquist S, Lofy KH, Wiesman J, Bruce H, et al. First case of 2019 novel coronavirus in the United States. New Engl J Med. 2020; 382(10):929-36.

10. Yao XH, Li TY, He ZC, Ping YF, Liu HW, Yu SC, et al. A pathological report of three COVID-19 cases by minimal invasive autopsies. Zhonghua Bing Li Xue Za Zhi. 2020;49(5):411-7.

11. Wolfel R, Corman VM, Guggemos W, Seilmaier M, Zange S, Muller MA, et al. Virological assessment of hospitalized patients with COVID-2019. Nature. 2020;581(7809):465-9.

12. Zhang W, Du RH, Li B, Zheng XS, Yang XL, Hu B, et al. Molecular and serological investigation of 2019-nCoV infected patients: implication of multiple shedding routes. Emerg Microbes Infect. 2020;9(1):386-9.

13. Wu Y, Guo C, Tang L, Hong Z, Zhou J, Dong X, et al. Prolonged presence of SARS-CoV-2 viral RNA in faecal samples. Lancet Gastroenterol Hepatol. 2020; 5(5):434-5.

14. Jones DL, Baluja MQ Graham DW, Corbishley A, McDonald JE, Malham SK, et al. Shedding of SARS-COV-2 in feces and urine and its potential role in 
person-to-person transmission and the environment-based spread of COVID-19. Sci Total Environ. 2020;749:141364.

15. To KK, Tsang OT, Leung WS, Tam AR, Wu TC, Lung DC, et al. Temporal profiles of viral load in posterior oropharyngeal saliva samples and serum antibody responses during infection by SARS-CoV-2: an observational cohort study. Lancet Infect Dis. 2020;20(5):565-74.

16. Ng SC, Chan FKL, Chan PKS. Screening FMT donors during the COVID-19 pandemic: a protocol for stool SARS-CoV-2 viral quantification. Lancet Gastroenterol Hepatol. 2020;5(7):642-3.

17. Corman VM, Landt O, Kaiser M, Molenkamp R, Meijer A, Chu DK, et al. Detection of 2019 novel coronavirus (2019-nCoV) by real-time RT-PCR. Euro Surveill. 2020;25(3):2000045

18. Loeffelholz MJ, Tang YW. Laboratory diagnosis of emerging human coronavirus infections - the state of the art. Emerg Microbes Infect. 2020; 9(1):747-56.

19. Acharya KR, Dhand NK, Whittington RJ, Plain KM. PCR inhibition of a quantitative PCR for detection of mycobacterium avium subspecies paratuberculosis DNA in feces: diagnostic implications and potential solutions. Front Microbiol. 2017:8:115.

20. Monteiro L, Bonnemaison D, Vekris A, Petry KG, Bonnet J, Vidal R, et al. Complex polysaccharides as PCR inhibitors in feces: Helicobacter pylori model. J Clin Microbiol. 1997:35(4):995-8.

21. Oikarinen S, Tauriainen S, Viskari H, Simell O, Knip M, Virtanen S, et al. PCR inhibition in stool samples in relation to age of infants. J Clin Virol. 2009: 44(3):211-4

22. Perchetti GA, Nalla AK, Huang ML, Zhu HY, Wei YL, Stensland L, et al. Validation of SARS-CoV-2 detection across multiple specimen types. I Clin Virol. 2020;128:104438.

23. Coryell MP, lakiviak M, Pereira N, Murugkar PP, Rippe J, Williams DB, et al. A method for detection of SARS-CoV-2 RNA in healthy human stool: a validation study. Lancet Microbe. 2021;2(6):e259-e66.

24. Prevention, CfDCa. DC 2019-novel coronavirus (2019-nCoV) real-time RT-PCR diagnostic panel. Centers for Disease Control and Prevention; 2020.

25. Vogels CBF, Brito AF, Wyllie AL, Fauver JR, Ott IM, Kalinich CC, et al. Analytical sensitivity and efficiency comparisons of SARS-CoV-2 RT-qPCR primer-probe sets. Nat Microbiol. 2020;5(10):1299-305.

26. Coryell MP, lakiviak M, Pereira N, Murugkar PP, Rippe J, Williams DB, et al. Validation and testing of a method for detection of SARS-CoV-2 RNA in healthy human stool. medRxiv. 2020; https://doi.org/10.1101/2020.11.09.2 0228601.

27. Manzoor SE, Zaman S, Whalley C, Inglis D, Bosworth A, Kidd M, et al. Multimodality detection of SARS-CoV-2 in faecal donor samples for transplantation and in asymptomatic emergency surgical admissions. F1000Research. 2021;10(373):373.

28. Zuo T, Liu Q, Zhang F, Lui GC, Tso EY, Yeoh YK, et al. Depicting SARS-CoV-2 faecal viral activity in association with gut microbiota composition in patients with COVID-19. Gut. 2021;70(2):276-84.

29. Team RC. R: a language and environment for statistical computing. Vienna: R Foundation for Statistical Computing; 2019. https://www.R-project.org/.

\section{Publisher's Note}

Springer Nature remains neutral with regard to jurisdictional claims in published maps and institutional affiliations.

Ready to submit your research? Choose BMC and benefit from:

- fast, convenient online submission

- thorough peer review by experienced researchers in your field

- rapid publication on acceptance

- support for research data, including large and complex data types

- gold Open Access which fosters wider collaboration and increased citations

- maximum visibility for your research: over $100 \mathrm{M}$ website views per year

At $\mathrm{BMC}$, research is always in progress.

Learn more biomedcentral.com/submissions 